\title{
Comparative measurements of total ozone amount and aerosol optical depth during a campaign at El Arenosillo, Huelva, Spain
}

\author{
A. de La Casinière ${ }^{1}$, V. Cachorro ${ }^{2}$, I. Smolskaia ${ }^{3}$, J. Lenoble ${ }^{1,4}$, M. Sorribas ${ }^{5}$, M. Houët ${ }^{4}$, O. Massot ${ }^{6}$, M. Antón ${ }^{7}$, and \\ J. M. Vilaplana ${ }^{5}$ \\ ${ }^{1}$ IRSA, Université Joseph Fourier, Grenoble, France \\ ${ }^{2}$ GOA, Universidad de Valladolid, Valladolid, Spain \\ ${ }^{3}$ now at: Institute for Meteorology and Climatology, Hannover University, Hannover, Germany \\ ${ }^{4}$ LOA, Université des Sciences et Technologies de Lille, Lille, France \\ ${ }^{5}$ ESAt-El Arenosillo-INTA, Huelva, Spain \\ ${ }^{6}$ CEMBREU, Briançon, France \\ ${ }^{7}$ Dept. of Physics, University of Extremadura, Badajoz, Spain
}

Received: 24 June 2005 - Revised: 10 October 2005 - Accepted: 11 October 2005 - Published: 21 December 2005

\begin{abstract}
A one week field campaign took place in September 2002 at El Arenosillo, Spain. The objective was to compare total ozone column (TOC) and aerosol optical depth $(A O D)$ from near ultraviolet to near infrared, measured by several Spanish and French instruments. Three spectroradiometers, Brewer, SPUV02, and LICOR, and a CIMEL photometer, have been used simultaneously and the results are presented for four clear days. TOC values are given by the Brewer instrument, and by SPUV02, using two different methods. The ground instruments compare satisfactorily (within 5 DU) and the values are consistent with TOMS data (within $10 \mathrm{DU}$ ).

$A O D$ from the various instruments are compared at seven different wavelengths between $320 \mathrm{~nm}$ and $1020 \mathrm{~nm}$ : the agreement is very good at 350,380 , and $870 \mathrm{~nm}$; at the four other wavelengths the difference is smaller than 0.03 , which can be explained by a relative difference of $4 \%$ only between the calibrations of the various instruments. Larger $A O D$ diurnal variations were observed at short wavelengths than in the visible and near infrared; this is most likely due to changes in aerosol size along the day, during the campaign.
\end{abstract}

Keywords. Atmospheric composition and structure, (Aerosols and particles; Middle atmosphere-composition and chemistry; Instruments and techniques) Instruments and techniques

\section{Introduction}

Intercomparison campaigns are of great interest for checking the maintenance and behaviour of different instrumentation used for the same type of field atmospheric measurements.

Correspondence to: A. de la Casinière

(alain.de-la-casiniere@ujf-grenoble.fr)
The measurement of solar ultraviolet radiation is not an easy task because of the low level of radiation, together with the variation of its magnitude in a short range of wavelengths (bear in mind that irradiance can change by three orders of magnitude in about $30 \mathrm{~nm}$ ). In this way, field intercomparison campaigns permit one to fix the level of uncertainties of instruments relative to each other, or the range of differences when distinct methods of measurements are used. The uncertainties and differences are transferred from the primary measurements to the derived quantities, such as ozone and aerosol optical depth.

The main objective of a French-Spanish cooperative programme (2002 Integrated Action Programme) was to intercompare the values of total ozone column (TOC), and of aerosol optical depth $(A O D)$ between $320 \mathrm{~nm}$ and $1020 \mathrm{~nm}$, measured with different instruments from both partners. The major campaign took place at the station "ESAt-El Arenosillo" near Huelva, on the southern coast of Spain, at the end of September 2002.

The Brewer spectroradiometer of El Arenosillo, and a Jobin Yvon UV spectroradiometer (hereafter referred to as SPUV02), brought by the IRSA group, measured the ozone column amount. The aerosol optical depth was measured by both of these instruments, also by the sunphotometer CIMEL of El Arenosillo (at 4 discrete visible wavelengths), part of the Aerosol Robotic Network (AERONET), and lastly, by a UV-visible LICOR1800 spectroradiometer brought by the GOA group.

As a secondary objective, intercomparisons are done between the global spectral irradiances given by the Brewer and the UV spectroradiometer SPUV02, and between the direct irradiances given by SPUV02 and by the LICOR1800. We must emphasize that Brewer and CIMEL are operational systems at the station of El Arenosillo (Spain) and SPUV02 at Briançon (France). 
The paper is structured as follows: Sect. 2 presents the conditions of the campaign, and the characteristics of the instruments, including their intercomparison for irradiance values. Section 3 concerns ozone value comparisons, together with the method used for the retrieval, and the same is done for aerosol measurements, in Sect. 4. The conclusions are in Sect. 5.

\section{Site, campaign, instruments and measured irradi- ances}

The site of the campaign is the atmospheric sounding station "ESAt-El Arenosillo", belonging to INTA (Instituto Nacional de Técnica Aeroespacial), which is located near Huelva $\left(37.1^{\circ} \mathrm{N}, 6.7^{\circ} \mathrm{W}, 17 \mathrm{~m}\right.$ asl) on the southwestern Spanish coast. The campaign was organised from 23 September to 1 October 2002. Measurements started on 25 September after the instruments brought from other sites were installed and calibrated. Although the sun often shines at this station, the weather was rather bad at the beginning of the campaign, corresponding to a raining period. During the four following days $(26,27,28,29$ September), the weather was somewhat better, with large sunny periods, although the sky was never completely cloudless; our analysis is limited to these four days. Then the sky was again overcast, and the instruments were dismounted.

The Brewer spectroradiometer operates routinely at El Arenosillo to provide ozone values and global UV irradiance, as part of the WMO network (Fioletov et al., 1999). This spectroradiometer works at five fixed wavelengths, 306.3, 310.1, 313.5, 316.8, and $320.1 \mathrm{~nm}$ for ozone retrieval. Aerosol optical depth can also be retrieved at these same wavelengths, as seen later (Sect. 4). At our request, spectral global irradiance measurements were performed, every $30 \mathrm{~min}$, or more often. The spectrum is scanned between 290 and $363 \mathrm{~nm}$, in about $7 \mathrm{~min}$; the resolution (Full Width at Half Maximum, FWHM) is $0.55 \mathrm{~nm}$ and the step of the scan is $0.5 \mathrm{~nm}$.

The UV spectroradiometer SPUV02, based on a Jobin Yvon HD10 double monochromator (Pachart, 1997; Pachart et al.; 2000, Masserot, 2001), belongs to the "Centre Européen Médical et Bioclimatologique de Recherche et d'Enseignement Universitaire" (CEMBREU) and operates regularly at Briançon in the French Alps, under the supervision of IRSA. A similar instrument, SPUV01, has taken part in an international intercomparison of 19 instruments. The agreement between the SPUV01 measurement and a reference spectrum based on six selected instruments was within 5\% (Bais et al., 2001: see Table 3). During the present campaign, it recorded the UV global spectral irradiance between 280 and $450 \mathrm{~nm}$ in about $5 \mathrm{~min}$, four times an hour (right on the hour, hour+20, hour+30, hour+50); the FWHM is $0.8 \mathrm{~nm}$, and the scan step $0.5 \mathrm{~nm}$. At the hour +10 and hour+40, a shadow disc blocks the direct solar beam, and the diffuse irradiance is recorded; the global irradiance at the same time is evaluated as the average of the two closest global measurements. The direct irradiance is therefore retrieved twice an hour, as the difference between the average global and the diffuse irradiances. The shadow disk presents a field of view (FOV) of $6.8^{\circ}$ which partly blocks the circumsolar diffuse flux and leads, in mean $A O D$ conditions, to an overestimation of the direct irradiance ranging from $0.5 \%$ to $2 \%$, depending on SZA and on wavelength; but no correction was applied.

The GOA UV-visible spectroradiometer LICOR1800, points to the Sun by means of a Sun-tracking system with a FOV of 2.3 deg (Durán, 1997; Cachorro et al., 1998). It scans the direct solar irradiance twice an hour, between 320 and $1000 \mathrm{~nm}$, in about $30 \mathrm{~s}$, with a step of $1 \mathrm{~nm}$; the FWHM is $6.3 \mathrm{~nm}$. More details about the instrument and calibration can be seen elsewhere (Cachorro et al., 1998; Martinez-Lozano et al., 2003).

The automatic CIMEL instrument from El Arenosillo observes the direct Sun and scans the sky at four wavelength channels, 440, 670, 870, $1020 \mathrm{~nm}$, according to AERONET protocols, as part of this network (Holben et al., 1998). Then $A O D$ data at these four wavelengths will be used for this comparative work.

In order to control the quality of the measurements, comparisons of irradiance spectra simultaneously recorded by the various instruments are done. SPUV02 and Brewer spectroradiometers measure global irradiance in the common range of $290-360 \mathrm{~nm}$. But as the two spectroradiometers have slightly different slit functions, their respective spectra are difficult to directly compare. Following a method proposed by de La Casinière et al. (2001), these spectra are first re-convoluted by a triangular slit function with the same FWHM; for global spectra from Brewer and SPUV02 the chosen common FWHM is $0.80 \mathrm{~nm}$. As an example of this comparison, the ratio of Brewer to SPUV02 global irradiances is presented in Fig. 1 for 4 spectra on 27 September under clear sky conditions. The mean ratio is about 0.98 , with a standard deviation of 0.015 , which is a very satisfactory agreement for UV spectroradiometry. The regular oscillations of about \pm 0.02 are likely due to a spectral variation of the calibration error for one or both instruments, as well as due to cosine errors not spectrally corrected; but these variations are too small to impact on the data quality.

For direct spectra from LICOR and SPUV02, the comparison is more delicate, because LICOR has a very low resolution, and also because its results are not expected to be good below approximately $320 \mathrm{~nm}$ (Cachorro et al., 2002). The chosen common FWHM is $6 \mathrm{~nm}$ and the spectra are reconvoluted in the range $305-394 \mathrm{~nm}$. Ratios are presented for the same 4 spectra of 27 September in Fig. 2. As expected, the oscillations are much larger than in the previous case; however, the mean ratio of direct spectra from LICOR and SPUV02 is found to be close to 1.00 , with a 0.055 standard deviation. This agreement is a necessary condition for a valid comparison between parameters retrieved from data recorded by the various instruments. 


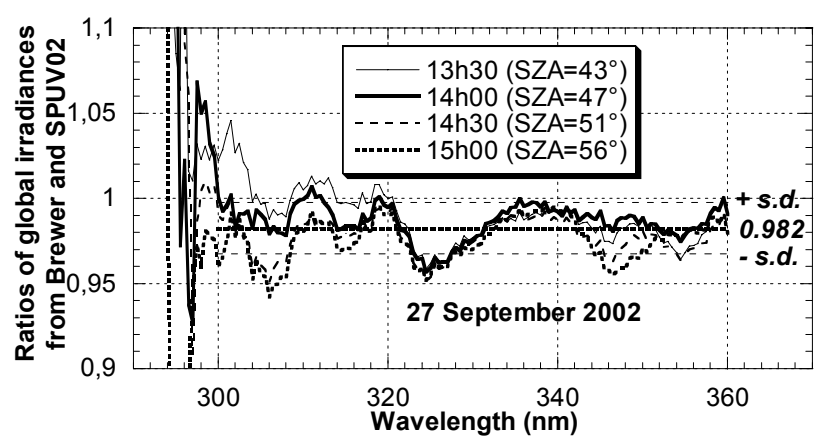

Fig. 1. Ratios of global irradiance spectra from Brewer spectroradiometer to global irradiance spectra from SPUV02 spectroradiometer simultaneously measured on a clear sky period (27 of September 2002).

\section{Ozone measurement comparison}

As we mentioned above, the Brewer of El Arenosillo is part of the global Brewer network (Fioletov et al., 1999). During the four mostly sunny days analysed, it routinely provided ozone values from direct Sun observations, approximately every $20 \mathrm{~min}$; some data are missing due to temporary obstructions of the Sun by clouds. Very few zenith sky observations have been performed, mainly in the early morning, but they are not used here.

Both the global and the direct irradiances measured by SPUV02 are used to retrieve the ozone total column amount. The analysis of the global irradiance relies on the method first proposed by Stamnes et al. (1991). The ratio of average irradiances in two narrow wavelength intervals, located, respectively, in the ozone absorption band and outside, is compared with model computed values for the same solar zenith angle, and for various ozone amounts; this comparison uses precomputed look-up tables (LUT). Masserot et al. (2002) obtained satisfying results using the wavelength intervals $305-310 \mathrm{~nm}$ and $340-345 \mathrm{~nm}$. Houët (2003), and Houet and Brogniez (2004) have improved the method by averaging the results obtained with five different spectral intervals.

The retrieval for "El Arenosillo" uses the LUTs built for Villeneuve d'Ascq in the north of France (Houët, 2003), because the altitude and the mean turbidity are similar. The major source of uncertainty in this method is due to clouds, for several reasons: the cloud extinction varies slightly with wavelength, and is not exactly the same in both channels, as assumed in the method; the variability of cloudiness during a spectral scan can distort the channel ratio; finally, the increased path length in a cloud can enhance the tropospheric ozone absorption. Only data with a solar zenith angle smaller than $75^{\circ}$ were used; from a detailed analysis of uncertainties, Bernhard et al. (2003) concluded that in this case, ozone is retrieved from global irradiance with an accuracy similar to TOMS and Dobson.

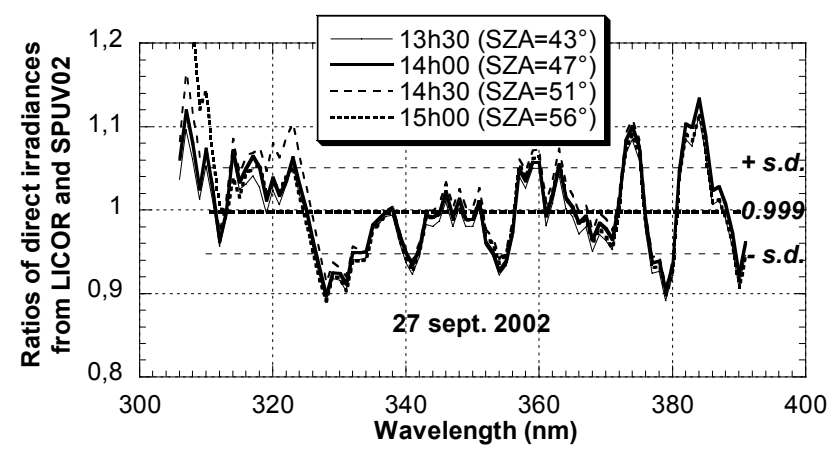

Fig. 2. Ratios of direct irradiance spectra from LICOR spectroradiometer to direct irradiance spectra from SPUV02 spectroradiometer simultaneously measured on a clear sky period ( 27 of September 2002).

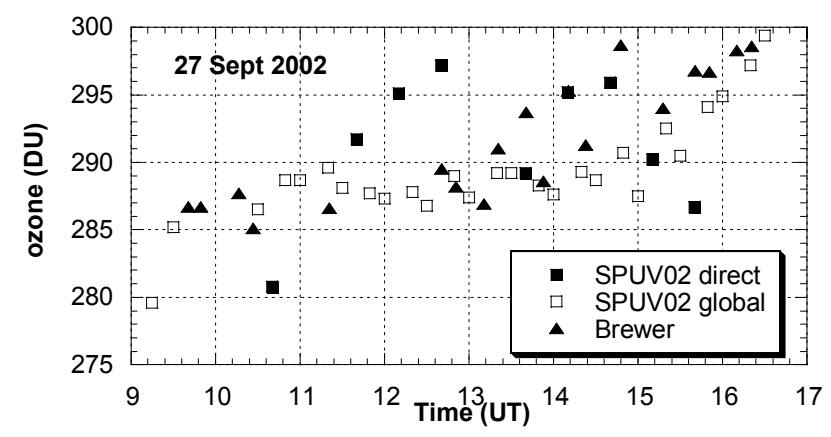

Fig. 3. Total ozone column amount measured at El Arenosillo, 27 September 2002; black squares from SPUV02 direct irradiance, open squares from SPUV02 global irradiance, and triangles from Brewer.

The direct irradiance is analysed according to the method detailed in Lenoble et al. (2004); instead of using ratios of irradiances at discrete wavelengths, as it is done for Brewer, we use the slope of the spectrum between 305 and $330 \mathrm{~nm}$, correlated with ozone cross sections. This avoids the difficulty of selecting discrete wavelengths in a spectrum which can never be perfectly corrected from a wavelength shift, and the method is very direct and easy to implement. The method is independent of the aerosol contribution and of the calibration uncertainty, as long as they are not wavelength dependent; the uncertainty due to these assumptions and to the wavelength scale uncertainty has been estimated at around 5 DU (Lenoble et al., 2004). Whereas the Brewer instrument points directly to the Sun and can measure at any time when there is no cloud on the direct solar beam, the SPUV02 instrument retrieves the direct irradiance as the difference between global and diffuse irradiances. This needs a clear, stable atmosphere during about $25 \mathrm{~min}$, necessary for the 3 spectral scans. Even limiting the retrieval to the period when the solar zenith angle does not vary rapidly, some of our results are impaired by variable cloudiness; this is definitely the weak point of the method. 
Table 1. Daily average ozone amount in DU with standard deviations in parenthesis, from Brewer, SPUV02 (two methods) and TOMS ozone.

\begin{tabular}{lllll}
\hline Date & Brewer & SPUV02/global & SPUV02/direct & TOMS \\
\hline 26 September & $293.1(4.9)$ & $286.4(12.7)$ & & 300 \\
27 September & $291.6(4.7)$ & $287.5(7.8)$ & $292.8(6.8)$ & 302 \\
28 September & $291.4(4.1)$ & $290.4(5.0)$ & $293.1(7.2)$ & 305 \\
29 September & $287.3(4.4)$ & $284.8(12.4)$ & & 298 \\
\hline
\end{tabular}

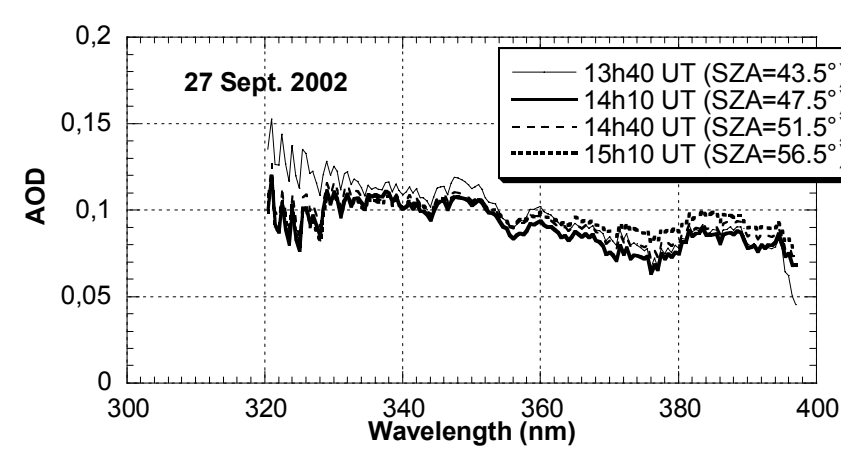

Fig. 4. Spectral UV variations of AOD from SPUV02 direct irradiances recorded on 27 September 2002.

The ozone amounts obtained from Brewer and by the two methods from SPUV02 are compared in Fig. 3 for 27 September 2002; the comparison is similar for the three other days, and shows a general good agreement between ozone retrieved from the SPUV02 data and the Brewer ozone. In the morning three erratic points (values larger than 300 DU or smaller than 270 DU) have been omitted; they are most likely due to clouds.

Table 1 summarises the daily average ozone amounts from Brewer and from SPUV02; we have added in this table the values given by the Total Ozone Mapping Spectrometer (TOMS) (McPeters et al., 1998); they are the operational daily gridded ozone product and correspond to an average of the pixels within a grid of $1^{\circ}$ latitude x $1.25^{\circ}$ longitude; the time of observation is close to local noon; their uncertainty is estimated at around 5 DU. On 26 and 29 September, only a few spectra, during limited periods of the day, allow a retrieval from the direct irradiance, and a daily average has not been given. The ground-based values of Brewer and SPUV02 agree very well, within their expected accuracy of a few DU. They are about $10 \mathrm{DU}$, or $3 \%$ lower than TOMS values; this is not a very large difference, however, it is somewhat higher than the expected uncertainties.

The systematic difference between ozone values from Brewer and TOMS have not been evaluated at the El Arenosillo station but we have evaluated the systematic differences given by Dobson and TOMS, and by Brewer and
Dobson. According to Vilaplana (2004), for the period 1996-2003, the ozone daily values given by TOMS are about $2 \%$ greater than the Dobson values with no seasonal trend. The mean annual relative difference between Brewer and Dobson (B-D/B) is $0.9 \%$ with a slight seasonality of 3\% (better agreement in summer). Hence, the TOMS ozone values, about $1-2 \%$ higher with respect to Brewer values, are systematically observed at El Arenosillo, also corroborated by the results given during this short campaign.

During a similar comparison at Briançon in the French Alps in 2000, we had found values from SPUV02 global irradiance of about $4 \%$ larger than the TOMS values (Masserot et al., 2002). From SPUV02 direct irradiance (clear days) at the same site in 2001 and 2002, we have also found SPUV02 values slightly larger (about $2 \%$ ) than TOMS (Lenoble et al., 2004). This different behavior between both sites may be due to their different geographical situations; in Briançon, the TOMS grid covers mountainous areas, whereas for El Arenosillo-Huelva, part of the grid is above the sea. Fioletov et al. (1999), in an extended study, compared TOMS and Dobson monthly means for 85 stations, and TOMS and Brewer for 30 stations; they found differences of around 2$2.5 \%$, either positive or negative, depending on the station.

\section{Aerosol measurement comparison in UV and visible- NIR bands}

One objective of this campaign was to compare $A O D$ retrieved from measurements by the three spectroradiometers, Brewer, LICOR1800 and SPUV02, together with the current $A O D$ monitoring of the CIMEL sunphotometer. Because of the rainy weather, unusual for the season, the atmosphere remained rather clean for the Huelva site, with moderate $A O D$ values during the Sun episodes.

The spectral UV direct irradiances measured by SPUV02 are used both to study $A O D$ wavelength dependence in the $\mathrm{UV}$ band and to assess the Angström turbidity factor $\beta$ and the Angström exponent $\alpha$. As an example, $A O D$ spectral variations in UV-A are shown in Fig. 4 at four times in the early afternoon on 27 September, with this period corresponding to the clearest sky conditions occurring during the campaign. 
It is usual to express $A O D$ spectral variations in terms of the 2 parameters $\alpha$ and $\beta$, defined by $A O D=\beta \lambda^{-\alpha}$ and retrieved from a linear fit between $A O D$ and the wavelength in a double logarithmic scale. Averaging the four spectra in Fig. 4 gives $\beta=0.019$ and $\alpha=1.6$ for the range $320-400 \mathrm{~nm}$. Nevertheless, it is well known that the Angström coefficients depend on the wavelength range considered, and the above $\alpha$ and $\beta$ values are not suitable for extrapolating $A O D$ at wavelengths in other bands. Moreover, minor spectral variations in the extraterrestrial flux error or in the instrument calibration error, can lead to large errors in $\alpha$, as discussed in Lenoble et al. (2002); they can also produce an artificial variability of $\alpha$, which shows further a strong dependence on SZA, according to results discussion in Cachorro et al. (2004). The difficulties are obviously the same when using the Angström coefficients determined in the visible band for extrapolating $A O D$ in the UV region.

After radiometric calibration, Brewer data in the six ozone channels could be used for retrieving AOD (Marenco et al., 2002), but the wavelength separation is too small (between 306 and $320 \mathrm{~nm}$ ) to obtain reliable values of the Angström coefficients. In such a case, negative $\alpha$ are even frequently obtained, as observed by Jarowslaski et al. (2003). Following Vilaplana et al. (2004), the negative $\alpha$ given by the Brewer instrument in El Arenosillo would be due to a calibration error.

$A O D$ values from the LICOR 1800 spectroradiometer are calculated at the fixed discrete wavelengths $350,380,440$, $670,870,1020 \mathrm{~nm}$, although this instrument provides a continuous spectrum from 320 to $1100 \mathrm{~nm}$ (Cachorro et al., 1998). These wavelengths are chosen outside the gas absorption bands.

As mentioned before in Sect. 2, the CIMEL instrument measures direct irradiance at 4 visible and near infrared wavelengths: 440, 670, 870 and $1020 \mathrm{~nm}$; the corresponding $A O D$ values used in the present study are those available in the AERONET database (Holben et al., 1998; Eck et al., 1999).

In the visible and near infrared band the $\alpha$ values given by CIMEL (from wavelengths 440,670, $870 \mathrm{~nm}$ ) and by Licor1800 (from the spectral windows [370-490 nm], [748$757 \mathrm{~nm}$ ], [776-782 nm], [862-872 nm]) compare reasonably well, as shown in Fig. 5.

Outside the gaseous line absorption spectra, $A O D$ is basically obtained from the following equation (if $S Z A<75^{\circ}$ ):

$A O D=\cos S Z A \ln \left(K_{d} I_{O \lambda} / I_{\lambda}\right)-R O D-k_{O} \Omega$.

Parameter $K_{d}$ is the ratio of actual to mean Sun-Earth distance, $I_{o \lambda}$ and $I_{\lambda}$ are, respectively, the extraterrestrial solar direct normal spectral irradiance and its value at ground level; $R O D$ is the Rayleigh optical depth, while $k_{O}$ and $\Omega$ are the ozone absorption coefficient and the amount of ozone.

When calculating $A O D$ from various instruments operating simultaneously, the same respective $S Z A, K_{d}, I_{o \lambda}, R O D$, $k_{O}$ and $\Omega$ values are used. Consequently, $I_{\lambda}$ is the only variable capable of introducing differences between the re-

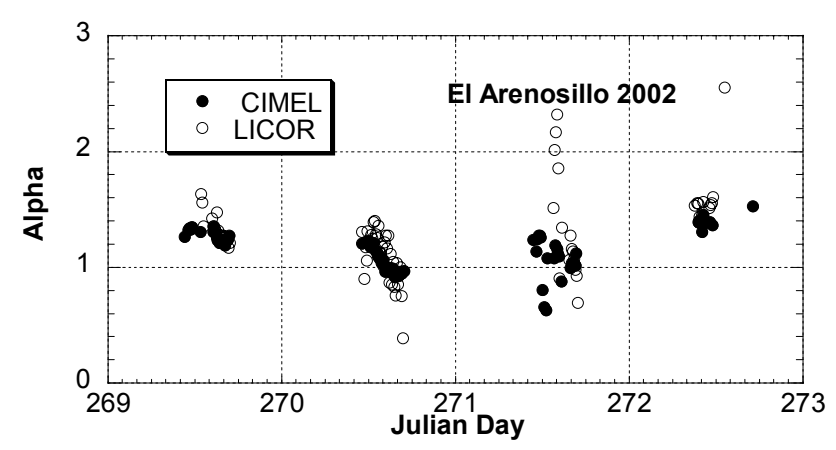

Fig. 5. Diurnal variations of the $\alpha$ coefficient from CIMEL and LICOR1800, for days 26 to 29 September (Julian days 269 to 272).

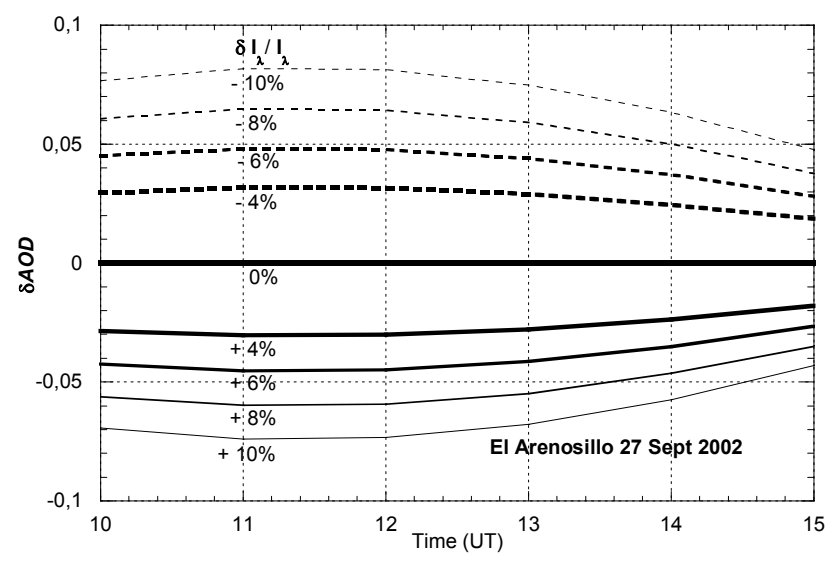

Fig. 6. Estimated difference between $A O D$ from two instruments as a function of time, on 27 September 2002, in El Arenosillo, for various relative differences between the irradiances given by the instruments.

sults. Then, let $\delta I_{\lambda}$ be the difference between the $I_{\lambda}$ values at a given wavelength from two instruments working simultaneously, the difference between the two $A O D$ may be written as:

$\delta A O D=-\cos S Z A \ln \left(1+\frac{\delta I_{\lambda}}{I_{\lambda}}\right)$.

As an example, the $\delta A O D$ variations on 27 September 2002 at El Arenosillo are presented in Fig. 6 for discrete $\delta I_{\lambda} / I_{\lambda}$ values, ranging from $-10 \%$ to $+10 \%$. Because the relative uncertainty of the $I_{\lambda}$ measurements in the UV band is $4 \%$, at least (for details, see Lenoble et al., 2002; Groebner et al., 2003; Martinez-Lozano et al., 2003), the relative difference $\delta I_{\lambda} / I_{\lambda}$ can reach $8 \%$ and the $\delta A O D$ differences as large as 0.06 are possible. Moreover, in the El Arenosillo campaign, the respective values of $S Z A, K_{d}, I_{o \lambda}, R O D, k_{O}$ and $\Omega$ used for calculating the various $A O D$ are not strictly identical, because of the different computer routines of the various instruments. Then, the true $\delta A O D$ can still be larger than indicated above, and does not follow exactly the diurnal variations plotted in Fig. 6. In any case it is large enough to 

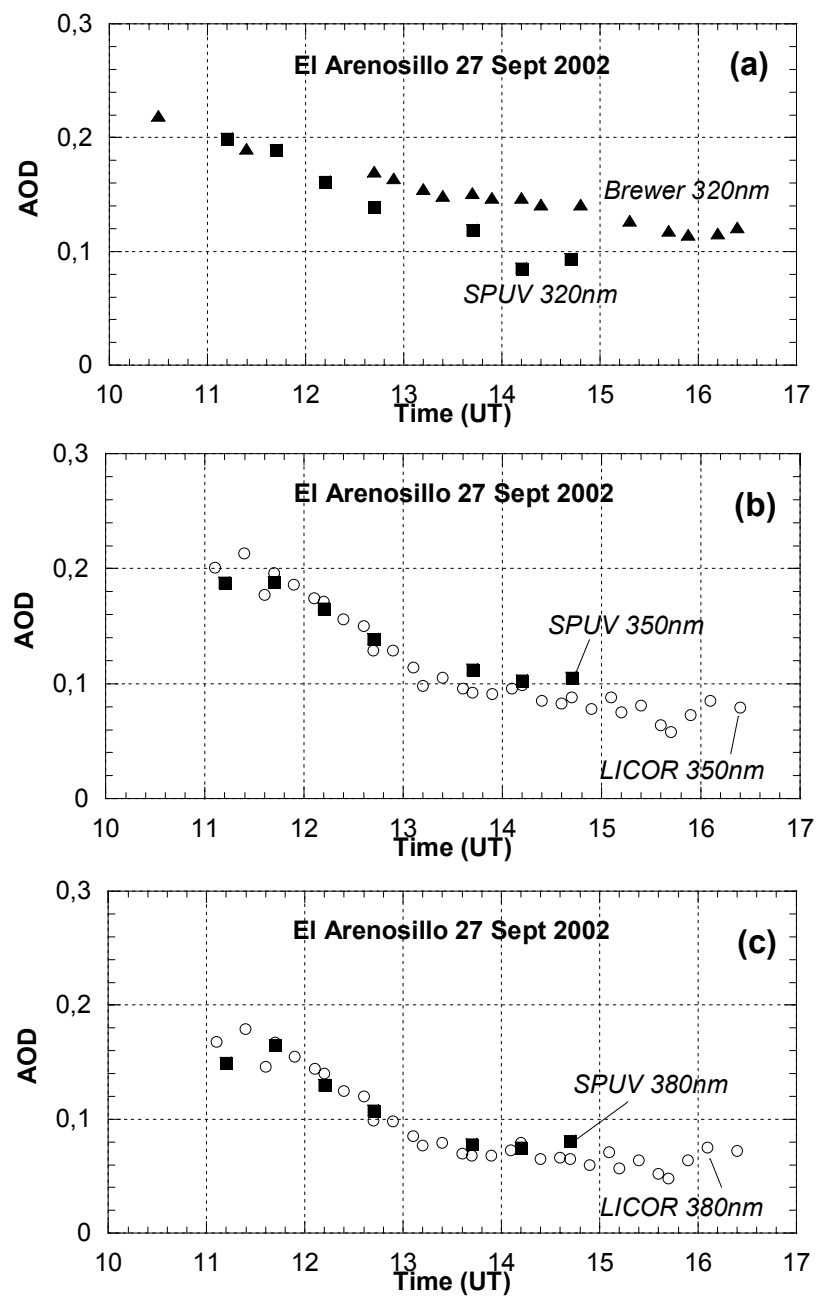

Fig. 7. Diurnal variations of $A O D$ in UV bands on 27 September 2002, following measurements from Brewer, LICOR and SPUV02 instruments.

explain the differences between the $A O D$ obtained from the various instruments.

Comparisons are presented in Fig. 7 for the UV band on 27 September 2002. In Fig. 7a (comparison SPUV-Brewer at $320 \mathrm{~nm}$ ) the differences are within the expected uncertainty previously discussed, while $A O D$ in Figs. $7 \mathrm{~b}$ and c (comparison SPUV-LICOR at 350 and $380 \mathrm{~nm}$ ) are in good agreement.

The link between the instrument calibration error responsible for $\delta I_{\lambda}$, and the apparent $A O D$ diurnal variations strongly correlated with $S Z A$ variations, has been extensively analysed and explained by Cachorro et al. (2003; 2004). On 27 September 2002, when solar noon is at about 11:40 UT, such a correlation could explain the decreasing $A O D$ observed from 11:30 to 16:30 UT in Fig. 7. But, if mainly governed by the diurnal $S Z A$ variations, the $A O D$ curve has to present at noon either a maximum or a minimum, depending on the sign of the calibration error; so the general decreasing in Fig. 7 would imply that all instruments would have a same
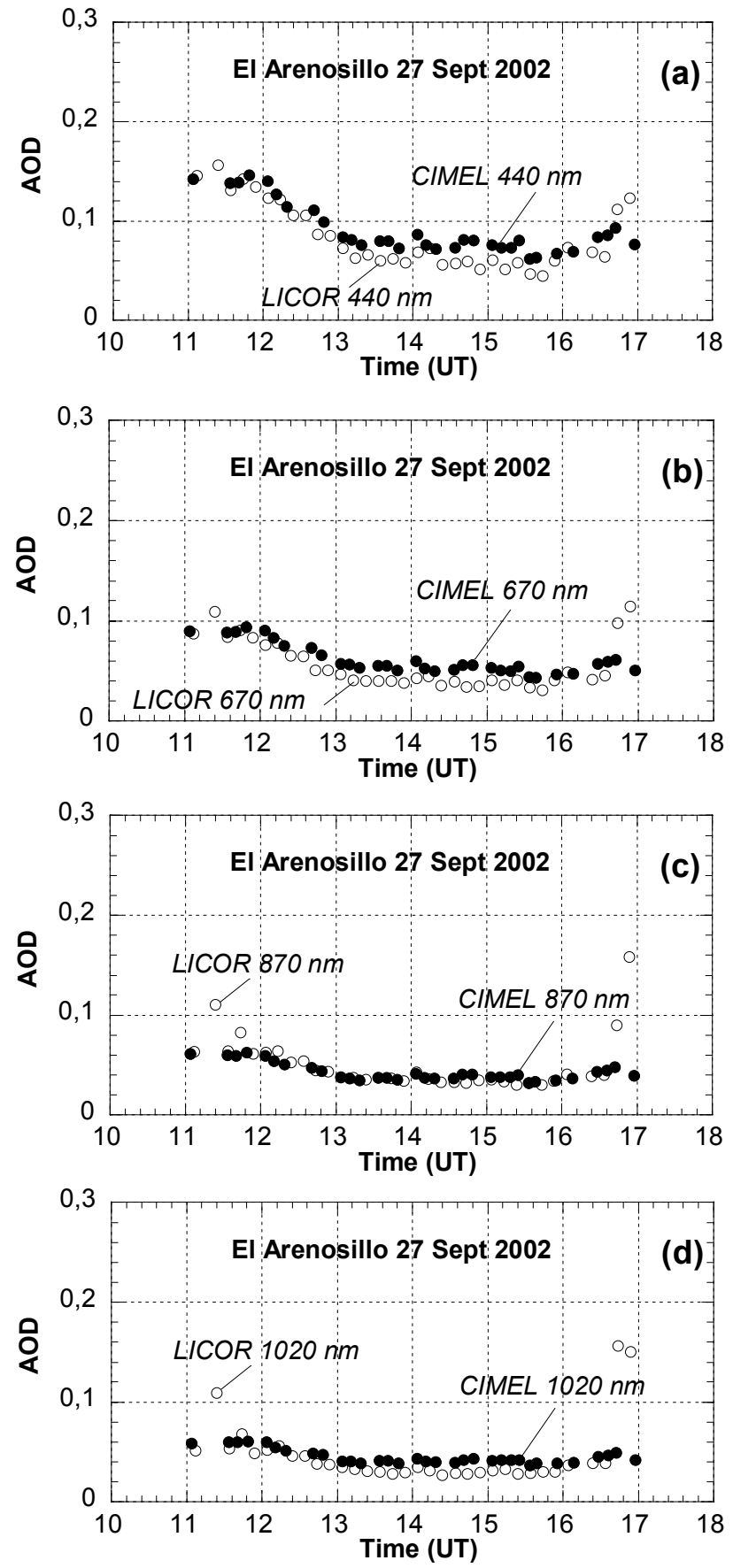

Fig. 8. Diurnal variations of $A O D$ in visible and near infrared bands on 27 September 2002, following measurements from CIMEL and LICOR instruments.

sign calibration error at all tested wavelengths. Because such an occurrence is very improbable, we can conclude that $A O D$ variations in Fig. 7 are due to real changes in aerosol content.

Comparisons between $A O D$ from the LICOR spectroradiometer and from the CIMEL sunphotometer were also carried out on 27 September 2002, but in visible and near infrared bands at the respective wavelengths $440,670,870$ and 
$1020 \mathrm{~nm}$. As shown in Figs. 8a, b, c and d, $A O D$ values from both instruments compare satisfactorily.

The ratios of $A O D$ at 11:00 to $A O D$ at 15:00 decrease regularly from 2.5 at $350 \mathrm{~nm}$ (Fig. 7) to 1.5 at $1020 \mathrm{~nm}$ (Fig. 8). This result indicates that the diurnal decrease of $A O D$ observed on 27 September is associated with a change in its spectral variation. In the morning, the $A O D$ increases faster toward short wavelengths than in the afternoon; this could be explained by a progressive change in the mean aerosol size along the day.

The results for the three other observation days are not presented, as they lead to similar conclusions in UV band, as well as in visible and near infrared bands.

\section{Conclusions}

Three spectroradiometers, Brewer, SPUV02, and LICOR, and a CIMEL photometer, have been used simultaneously during four days in September 2002, at El Arenosillo, Spain. After correcting for their different resolutions, spectral global irradiances measured by Brewer and SPUV02 instruments are in very good agreement, with a mean ratio of 0.98 , and a standard deviation of 0.015 . Since Brewer is a standard instrument part of an international network, we consider that this result validates the calibration of SPUV02 performed at its home site in Briançon, France.

The comparison of direct spectral irradiance measured by SPUV02 and LICOR presents a mean ratio close to 1 , with a standard deviation of 0.055 .

Total ozone column values are given by the Brewer instrument and by SPUV02, using two different methods. The ground instruments compare satisfactorily (within $5 \mathrm{DU}$ ) for TOC, whose values are consistent with TOMS data, at least for clear sky periods.

$A O D$ from the various instruments are compared at seven different wavelengths between $320 \mathrm{nn}$ and $1020 \mathrm{~nm}$ : the agreement is good at 350,380 , and $870 \mathrm{~nm}$; at the four other wavelengths the difference, which is smaller than 0.03 , can be explained by a relative difference of about $4 \%$ between the calibrations of the various instruments. Considering the performances of the present best spectroradiometers, a $4 \%$ difference between irradiances from two distinct instruments is a satisfactory result, particularly at short wavelengths.

Extending $A O D$ measurements, generally done in visible and near infrared, to UV wavelengths, makes the detection of possible changes in aerosol properties easier. Accuracy of $A O D$ at short wavelengths, especially for low AODs, is limited by the difficulty of UV spectroradiometer calibration.

The objectives of the campaign have been achieved, and confidence has been gained in $T O C$ and $A O D$ measurements performed by the different instruments.

Acknowledgements. This activity has been developed with the financial support of the Spanish Research Commission CICYT under the program of "Acciones Integradas HF2001-0069" and also under the project REN2002-00966. CEMBREU kindly lends SPUV02 instrument for the duration of the campaign; Hadrien Sevray, Technician at CEMBREU, took part in the campaign and was of a great help. The French participants appreciated the hospitality and support at INTA. The comments of an anonymous reviewer strongly helped to improve the manuscript.

Topical Editor F. D' Andrea thanks two referees for their help in evaluating this paper.

\section{References}

Bais, A. F., Gardiner, B. G., Slaper, H., Blumthaler, M., Bernhard, G., McKenzie, R., Webb, A. R., Seckmeyer, G., Kjeldstad, B., Koskela, T., Kirsch, P. J., Gröbner, J. Kerr, J. B., Kazadzis, S., Leszczynski, K., Wardle, D., Josefsson, W., Brogniez, C., Gillotay, D., Reinen, H., Weihs, P., Svenoe, T., Eriksen, P., Kuik, F., and Redondas, A.: SUSPEN intercomparison of ultraviolet spectroradiometers, J. Geophys. Res., 106, 12 509-12 525, 2001.

Bernhard, G., Booth, C. R., and McPeters, R. D.: Calculation of total column ozone from global UV spectra at high latitudes, J. Geophys. Res. , 108(D17), 4532, doi:10.1029/2003JD003450, 2003.

Cachorro, V. E., Utrillas, P., Vergaz, R., Durán, P., de Frutos, M. A., and Martinez-Lozano, J. A.: Determination of atmospheric water vapor content in the $940 \mathrm{~nm}$ band using moderate spectral resolution measurements of direct solar irradiance, Applied Optics 37, 4678-4689, 1998.

Cachorro, V. E., Vergaz, R., Martin, M. J., de Frutos, A. M., Vilaplana, J. M., and de la Morena, B.: Measurements and estimation of the tropospheric aerosol optical depth at UV spectral range, Ann. Geophys., 20, 565-574, 2002

SRef-ID: 1432-0576/ag/2002-20-565

Cachorro, V. E., Toledano, C., de Frutos, A. M., Vilaplana, J. M., Romero, P. M., and Cuevas, E.: Retrieval of aerosol optical depth (AOD) by the Brewer instrument: Detection and correction of calibration problem by a new method,Eight Biennial Brewer Users Working Group Meeting, El Arenosillo, 2003.

Cachorro, V. E., Romero, P. M., Toledano, C., Cuevas, E., and de Frutos, A. M.: The fictitious diurnal cycle of aerosol optical depth: a new approach for "in situ" calibration and correction of $A O D$ data series, J. Geophys. Letter, 31(12), L12106, doi:10.1029/2004GLO19651, 2004.

de La Casinière, A., Cabot, T., Touré, M. L., Masserot, D., and Lenoble, J.: Method for correcting the wavelength misalignment in measured ultraviolet spectra, Appl. Optics, 40, 6130-6135, 2001.

Durán, P.: Medidas espectroradiométricas para la determinación de componentes atmosféricos (ozono, vapor de agua y aerosoles) y modelización del intercambio radiativo en la atmósfera, Ph. D. Dissertation, Department of Agroforestal Sciences, University of Valladolid, Spain, 1997.

Eck, T. F., Holben, B. N., Reid, J. S., Dubovik, O., Smirnov, A., Neill, N. T., Slutsker, I., and Kinne, S.: Wavelength dependence of the optical depth of biomass burning, urban, and desert dust aerosols, J. Geophys. Res., 104, 31 333-31 349, 1999.

Fioletov, V. E., Kerr, J. B., Hare, E. W., Labow, G. L., and McPeters, R. D.: An assessment of the world ground-based total ozone network performance from comparison with satellite data, J. Geophys. Res., 104, 1737-1747, 1999.

Gröbner, J. and Meleti, C.: Aerosol optical depth in the UVB and visible from Brewer spectrophotometer direct irradiance mea- 
surements: 1991 to 2002, J. Geophys. Res., 108, D24, 4800 doi:10.1029/2003JD, 2003.

Holben, B. N., Eck, T. F., Slutsker, I., Tanré, D., Buis, J. P., Setzer, A., Vermote, E., Reagan, J. A., Kaufman, Y. F., Nakajima, T., Lavenu, F., Jankowiak, I., and Smirnov, A.: AERONET, a federated instrument network and data archive for aerosol characterization, Remote Sens. Environ., 66, 1-16, 1998.

Houët, M.: Spectroradiométrie du rayonnement solaire UV au sol: Améliorations apportées à l'instrumentation et au traitement des mesures. Analyse pour l'évaluation du contenu atmosphérique en ozone et aérosols, Ph.D. Dissertation, Université des Sciences et Technologies de Lille, France, 2003.

Houët, M. and Brogniez, C.: Ozone column retrieval from solar UV irradiance measurements at ground level: Sensitivity tests and uncertainty estimation, J. Geophys. Res., 109, D15302, doi:10.1029/2004JD004703, 2004.

Jaroslawski, J., Krzyscin, J. W., Puchalski, S., and Sobolewski, P.: On the optical thickness in the UV range: Analysis of the groundbased taken at Belsk, Poland. J. Geophys. Res., 108, D23, 4722 doi:10.1029/2003JD003571, 2003.

Lenoble, J., Martin, T., Blumthaler, M., Philipona, R., Albold, A., Cabot, T., de La Casinière, A., Gröbner, J., Masserot, D., Müller, M., Pichler, T., Seckmeyer, G., Schmucki, D., Touré, M.L., and Yvon, A.: Retrieval of ultraviolet aerosol optical depth during a spring campaign in the Bavarian Alps, Appl. Optics, 41, 16291639, 2002.

Lenoble, J., de La Casinière, A., and Cabot, T.: Analysis of direct solar ultraviolet irradiance measurements in the French Alps. Retrieval of turbidity and ozone column amount, Appl. Optics, 43, 3133-3139, 2004.

Marenco, F., di Serra, A., and De Luisi, J.: Methodology for determining aerosol optical depth from Brewer 300-320 nm ozone measurements, Applied Optics, 41, 1805-1814, 2002.
Martinez-Lozano, J. A, Utrillas, M. P., Pedros, R., Tena, F., Lorente, J., de Cabo, X., Diaz, J. P., Exposito, F. J., Cachorro, V. E., and Vergaz, R., and Carreño, V.: Spectroradiometers characterization in the visible range $(400-700 \mathrm{~nm})$ by intercomparison methods, Journal of Atmospheric and Oceanic Technology, 20 (7), 9971010, 2003.

Masserot, D.: Spectroradiométrie du rayonnement solaire UV: Mesures et Analyses, Ph.D. Dissertation, Université des Sciences et Technologies de Lille, France, 2001.

Masserot, D., Lenoble, J., Brogniez, C., Houët, M., Krotkov, N., and McPeters, R.: Retrieval of ozone column from global irradiance measurements and comparison with TOMS data, Geophys. Res. L., 29, doi:10129/2002GL014823, 2002.

McPeters, R., Bhartia, P. K., Krueger, A. J., Herman, J. R., Wellemeyer, C. G., Seflor, C. J., Jaross, G., Torres, O., Moy, L., Labow, G., Byerly, W., Taylor, S. L., Swissler, T., and Cebula, R.P.: Earth Probe Total Ozone Mapping Spectrometer (TOMS) Data Products User's Guide, NASA/TP-1998-206895, 1998.

Pachart, E.: Mesure et modélisation du rayonnement ultraviolet au sol, Ph. D. Dissertation, Université des Sciences et Technologies de Lille, France, 1997.

Pachart, E., Lenoble, J., Brogniez, C., Masserot, D., and Bocquet, J. L.: Consistency tests on UV spectral irradiance measurements using modelling and a broadband instrument, J. Geophys. Res., 105, 4851-4856, 2000.

Stamnes, K., Slusser, J., and Bowen, M.: Derivation of total ozone abundance and cloud effects from spectral irradiance measurements, Appl. Optics, 30, 4418-4426, 1991.

Vilaplana, J. M.: Medida y análisis del ozono y de la radiación solar ultravioleta en El Arenosillo-INTA, (Huelva), PhD. Dissertation, Department of Optics, University of Valladolid, Spain, 2004. 